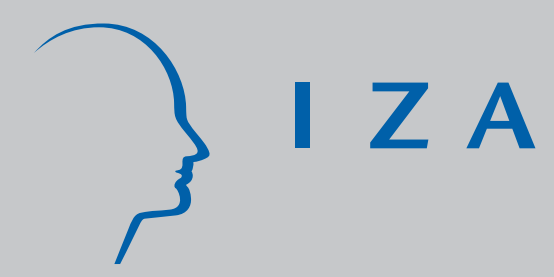

IZA DP No. 2116

Wage Rigidity or Fiscal Redistribution?

The Unemployment Bias of Time Consistent

Redistributive Policies

Etienne Lehmann

May 2006 


\title{
Wage Rigidity or Fiscal Redistribution? The Unemployment Bias of Time Consistent Redistributive Policies
}

\author{
Etienne Lehmann \\ ERMES, University Paris 2 Panthéon Assas \\ and IZA Bonn
}

Discussion Paper No. 2116

May 2006

IZA
P.O. Box 7240
53072 Bonn
Germany

Phone: +49-228-3894-0

Fax: +49-228-3894-180

Email: iza@iza.org

\begin{abstract}
Any opinions expressed here are those of the author(s) and not those of the institute. Research disseminated by IZA may include views on policy, but the institute itself takes no institutional policy positions.

The Institute for the Study of Labor (IZA) in Bonn is a local and virtual international research center and a place of communication between science, politics and business. IZA is an independent nonprofit company supported by Deutsche Post World Net. The center is associated with the University of Bonn and offers a stimulating research environment through its research networks, research support, and visitors and doctoral programs. IZA engages in (i) original and internationally competitive research in all fields of labor economics, (ii) development of policy concepts, and (iii) dissemination of research results and concepts to the interested public.
\end{abstract}

IZA Discussion Papers often represent preliminary work and are circulated to encourage discussion. Citation of such a paper should account for its provisional character. A revised version may be available directly from the author. 


\section{ABSTRACT}

\section{Wage Rigidity or Fiscal Redistribution? The Unemployment Bias of Time Consistent Redistributive Policies}

Because of Time Inconsistency considerations, policymakers underestimate the drawbacks of wage rigidity as a redistributive tool. Consequently, they redistribute inefficiently income from high to low skilled workers. They typically implement too much wage rigidity whereas other means (in particular fiscal transfers) could achieve the same redistributive goal with less perverse effect on unemployment. Time inconsistency is more likely due to lack of credibility than to the short-term horizon of policymakers. Hence, policymaking processes should be reformed towards more transparent and binding agreements between government and social partners.

JEL Classification: D78, H2, J68

Keywords: unemployment, inequality, wage rigidity, time inconsistency

Corresponding author:

Etienne Lehmann

ERMES, University Paris 2 Panthéon Assas

12, Place du Panthéon

75230 Paris Cedex 5

France

Email: elehmann@u-paris2.fr

\footnotetext{
* I wish to thank participants at seminars in Australian National University, University of Melbourne, University of Western Sydney, University of Sydney, University Paris 1, University of Saint-Etienne, University of Paris 2, Catholic University of Louvain (la Neuve), CREST, EPCS, T2M, EEA, ESEM and the workshop 'recent advances in political economics' with a particular mention to Y. Algan, M. Bacache, R. Boucekkine, B. Breuning, P. Cahuc, B. Chapman, Y. Chou, D. Cobb-Clark, B. Cockx, B. Decreuse, D. Dharmapala, D. Doiron, R. Durr, T. Gorgens, B. Gregory, H. Kempf, C. Lucifora, D. Meurs, A. Pagan, G. Saint-Paul, B. Salanié, P. Satya, A. Sengupta, C. Skeels, H Sneessens, T. Piketty and B. Van der Linden. Usual caveats apply.
} 


\section{Introduction}

Different types of policies can be used to redistribute incomes from high to low skilled workers. Each of them implies different types of distortions. Wage rigidity such as minimum wage or strong unions, increase low skilled workers' gross wage, which may be detrimental to the low skilled labor demand. Fiscal redistribution distorts the labor supply and implies tax-collecting costs. In this paper, I argue that the politically chosen combination of redistributive tool is inefficient. Because of time inconsistency considerations, policymakers may underestimate the drawbacks of wage rigidities. Therefore, low skilled workers' gross wage may be too high which worsen unemployment, while using fiscal transfer could achieve the same redistributive goal with less perverse effect on unemployment ${ }^{1}$.

I develop this argument in a simplistic two skilled labor demand framework. Perfect competition in the skilled labor market, inelastic labor supplies and a "small" tax collecting cost are assumed. Hence, the only source of unemployment in the model is a too high level of the low-skilled gross wage, through a legally binding minimum wage. Consider then a substitution of fiscal transfer for wage regulation that keeps unchanged income levels for low skilled workers. This implies a decrease in minimum wage and a rise in low skilled specific transfer. Such policy switch has two opposite effects. First, the decrease in minimum wage increases total output though a rise in low skilled labor demand. Second, a rise in the tax rate may be required ${ }^{2}$, so the tax collecting costs are raised. If tax collecting costs are "small" enough, this policy switch is Pareto improving. Hence, in this framework, the optimal policy, uses fiscal transfers only and do no implement any binding minimum wage.

However, this policy is Time Inconsistent (TI). Once firms have set their labor demand, the policymaker does no longer consider the employment effects of its choices. Hence, the best Time Consistent (TC) policy uses only minimum wage and does not use fiscal redistribution so as to minimize the distortions induced by fiscal transfers. When the policymaking process has to be Time Consistent, firms anticipate a higher minimum wage and therefore a lower employment level for unskilled workers. Hence, time consistency in redistributive politics leads to an "unemployment bias", just as time consistency in monetary economics leads to an "inflation bias". In this retrospect, there is a close analogy between the present argument and the positive theory of inflation of Kydland and Prescott (1977) or Barro and Gordon (1983).

I then ask the following question: what are the institutional environments that force

\footnotetext{
${ }^{1}$ Piketty (1999) argues that unemployment would have been lower in France with similar inequality if more fiscal redistribution instead of wage regulation were implemented. Hence many economists since Drèze and Malivaud (1994) have argued in favor of fiscal stimulations of low skilled labor demand.

${ }^{2}$ Except if a Laffer effect is at work, which does not appear to be the case.
} 
redistributive policies to be TC or let redistributive policies be TI? Put differently what are the institutional determinants of the "unemployment bias"? These questions are first raised theoretically and then empirically.

From a theoretical viewpoint, time consistency constraints can arise for two different reasons (see Cohen and Michel 1988). First, the policymaker may be available to commit only over a short term horizon. Over this horizon, the relevant elasticity of the labor demand is smaller than the long-run elasticity because of adjustment costs. This leads to an underestimation of the drawbacks of wage regulation. I call this the "short-term argument". Second, policymakers may be unable to make any binding commitments over their policies. Thus, firms believe that redistribution will occur through wage regulation only. They reduce their labor demand independently of policymakers' announces. Policymakers then observe their inability to influence firms' expectations over the wage structure, so they believe they are unable to change employment levels. Hence, they effectively choose the redistributive policies ignoring their impact on employment. I call this the "lack of credibility argument".

The distinction between these two types of Time Consistency constraints has important consequences on the way the policymaking process should be reformed. If the short term argument prevails, then more adjustment costs decreases the implicit elasticity of the labor demand that is considered by the policymaker. Time consistency constraint can then be relaxed by decreasing these costs through a decrease in employment protection. Conversely, if the "lack of argument" prevails, Time consistency constraint can be relaxed by delegating redistributive policies from government to the social partners, or by making with social partners public and binding agreements about redistributive policies. The "Dutch model" (see Nickell and Van Ours (2000)) since the Wasenaar agreement is a good illustration of the type of reform I have here in mind. A dynamical extension of the theoretical model to introduce adjustment costs evaluates which argument is the most plausible. Numerical simulations suggest that the "short-term" argument does not dramatically change the policy chosen, so the "lack of credibility" argument sounds the most plausible.

The empirical section uses a panel of European countries. The identification of TI versus TC policymaking processes is based on the following theoretical prediction. Under TC policymaking process, there is an increasing relation between employment levels and earnings inequality since lower inequality is then only obtained though a rise in minimum wage. Conversely, this is not the case with TI policymaking process that induces fiscal transfers that preserve employment. I then evaluate whether employment rates are increasing with earnings inequality and which kinds of institutions make this relation stronger. 
My empirical estimates conclude that lower wage coordination makes the link between employment and inequality stronger whereas employment protection does not have the theoretically expected effect. This suggests that improving the credibility of the wage setting process though a higher coordination seems important to do, whereas decreasing employment protection seems more anecdotal in this retrospect.

The paper is organized as follows. The related literature is exposed in section II. Section III presents the model. Section IV solves the static case, whereas Section V considers its dynamical extension. Section VI is devoted to the empirical evaluation and section VII concludes.

\section{Related literature}

This paper is connected to different strands of the literature. The first one concerns the opportunity of a binding minimum wage policy. The main assumption is that from a normative viewpoint, it is socially desirable to substitute fiscal transfers for wage regulation. This view is supported by the second theorem of welfare economics. According to it, an efficient redistribution can be achieved by fiscal means provide perfect competition remains. But such a view is obviously far too simplistic. Actually, many have very convincingly argued that minimum wage policies may have a welfare-enhancing role. First, lump-sum transfers are not available, so the second theorem of welfare economics is not relevant. When only linear taxes are available (as in Allen 1987 and Guesnerie and Roberts 1987), when a negative income tax is unfeasible (Drèze and Gollier 1993) or when the government faces informational constraints with respect to workers productivity (Marceau and Boadway and 1994 or Boadway and Cuff 2001), a minimum wage may have a role to play as a second-best redistributive tool. However, Allen (1987) shows that when nonlinear income tax are feasible but informational constraints binds, minimum wage is not welfare improving. Hungerbühler et alii (2006) show in unemployment-matching version of the optimal non linear income tax framework that optimal unemployment rates and optimal gross wages are inefficiently low at the second-best optimum. Hence, optimal redistribution should happen through a decrease in gross wages. Another literature assumes the existence of a market failure that requires a specific public policy. Stigler (1946) shows that when firms have some monopsony power, a rise in the minimum wage can increase the level of employment (see Card and Krueger (1994) or Dolado and alii (1996) or Manning (2003) for empirical discussions). Cahuc and Michel (1996) and Agell and Lommerud (1997) consider the externalities induced by the human capital acquisition. Cahuc, SaintMartin and Zylberberg (2000) consider an economy where skilled wages are negotiated. The optimal policy should therefore use a combination of both wage regulation and fiscal 
transfers. However, in many European countries, wage rigidity is so important that it might remains desirable to substitute (at least partly) fiscal transfers for it as argued by Drèze and Malinvaud (1994) or Piketty (1999). All this literature is essentially normative whereas the present article wishes to explain why redistributive tool are chosen inefficiently from a political economics viewpoint. It thus simplifies a lot the working of the labor market. If all of the abovementioned realistic features were incorporated in the model, the bias highlighted in this paper of too much wage rigidities and too few fiscal transfers would remain. The superiority of fiscal means is here only a simplifying assumption and shpuld not be understood as a normative argument against minimum wages policies.

There is a growing literature on the politico-economics of minimum wages that includes Saint-Paul (1996a,b and 2000), Sobel (1999), Epstein and Nitzan (1999) or Decreuse and Wigniolle (2002) among others. Basically this literature assumes that policies are the outcome of an explicit and micro-founded game and so differ to the ones that maximize a social welfare criterion. In these papers, policy-makers' objectives are distinct from social welfare for different reasons. For instance, according to the political insider theory of Saint-Paul (1996a,b and 2000) an opportunistic politician pays too much attention to the median voter's interest that must be a low-skilled insider whose exposure to unemployment is lower than the average. Decreuse and Wigniolle (2002) assumes the median voter is a middle aged worker whose protection against unemployment is higher than young workers. Epstein and Nitzan (1999) consider the influences of lobbying activities over the determination of the minimum wage level. In their setting too, outsiders' objectives are underrepresented. Sobel (1999) gives some evidences that the minimum wage is not set in the US according to normative issues but is the outcome of a political process. The present paper is not interested in the determinants of low skilled workers political power. Conversely, it focuses on the way Time Consistency constraints on the policymaking process lead to inefficient redistributive policies that worsen unemployment, whereas a Pareto superior outcome could be reached. In this retrospect, my problematic is similar to Coate and Morris (1995), even if the economic model and the answer are different.

Finally, there is a growing literature that tries to account for the different time pattern of unemployment across OECD countries (see among others Nickell 1997, Blanchard and Wolfers 1999, Belot Van Ours 2000, Bertola, Blau and Kahn 2001 Nickell, Nuziata, Ochel and Quintini 2001 or Algan Cahuc and Zylberberg 2002). The main explanation is that different institutions in different countries induce different responses to shocks that had hit roughly identically OECD economies since the 60ies. Belot and Van Ours (2000) and Nickell and al. (2001) contributed very significantly to this literature, in part due to the time varying measures of institutions they get. As Bertola et alii, the paper uses inequality 
measures as a macroeconomic explanatory "shock" that leads to different unemployment pattern due to different institutions.

\section{The model}

\section{III.1 Technology and preferences}

There are two types of workers in the economy: high and low skilled, respectively indexed by $i=h, l$. Each worker is risk averse, supplies a single unit of labor and enjoys utility from consumption only, according to the utility function $v($.$) , with v^{\prime}()>$.0 and $v^{\prime \prime}()<$.0 . High skilled labor market is competitive whereas low skilled one may be characterized by a minimum wage and by unemployment benefits. High skilled workers are always employed, receive gross wage $W_{h}$, pay a payroll tax $\tau$, and consume the net wage $w_{h}=(1-\tau) W_{h}$. Low skilled workers can either be employed or unemployed. Low skilled employed workers, receive gross wage $W_{l}$, pay the payroll tax $\tau$, receive a subsidy $s \geq 0$, and consume the net wage $w_{l}=(1-\tau) W_{l}+s$. Low skilled unemployed workers receive unemployment benefits $b$ and pay no tax. Unemployment benefits $b$ are lower than after-tax income $w_{l}$, so $w_{l} \geq b$ and low skilled workers always prefer to work. Both high and low skilled workforces are normalized to 1 . The number of employed low skilled workers is denoted by $L \leq 1$.

A representative firm produces the consumption good thanks to high skilled labor $H$ and low skilled labor $L$, according to the production function $F(H, L)$. The technology is standard and neo-classical. It exhibits constant return to scale. The good is sold on a perfectly competitive market at a price normalized to 1 . Since high skilled labor market is perfectly competitive, one gets $H=1$. Aggregate output thus depends only on low skilled employment according to $f(L) \equiv F(1, L)$ with:

$$
f^{\prime}(.)>0 \quad f(L)-L \cdot f^{\prime}(L)>0 \quad f^{\prime \prime}(.)<0
$$

Profit maimization implies:

$$
W_{l}=F_{2}^{\prime}(1, L) \equiv f^{\prime}(L)
$$

The constant return to scale assumption gives

$$
f(L)=W_{h}+L \cdot W_{l} \quad \Rightarrow \quad W_{h}=f(L)-L \cdot f^{\prime}(L)
$$

Since capital is not a factor production and skilled labor market is competitive, skilled workers gross wage is similar to a profit. Once employed low skilled workers have been paid, the remaining output corresponds to high skilled workers' gross income. The after tax incomes are:

$$
\begin{aligned}
& w_{h}=(1-\tau)\left(f(L)-L \cdot f^{\prime}(L)\right) \\
& w_{l}=(1-\tau) f^{\prime}(L)+s
\end{aligned}
$$


The elasticity of substitution between high and low skilled employment is denoted $\sigma$, with:

$$
\sigma(L)=\frac{f^{\prime}(L) \cdot\left(f(L)-L f^{\prime}(L)\right)}{-L \cdot f^{\prime \prime}(L) \cdot f(L)}>0
$$

The tax levied amounts to $\tau \cdot W_{h}+\tau \cdot L \cdot W_{l}=\tau \cdot f(L)$. Policymaker's expenditures are unemployment benefits $(1-L) b$ and subsidies for low skilled jobs $L \cdot s$. However, the technology of taxation is imperfect and for 1 unit of tax levied, only $1-\varepsilon$ unit is available for expenditures, with $\varepsilon>0$. $\varepsilon$ is the tax collecting cost parameter. It may correspond to the time or ressources spent by firms in collecting information (see also the discussion in Saint-Paul (1994)). This time is lost for the production and is increasing in the tax pressure ${ }^{3}$. The budget constraint hence writes:

$$
(1-\varepsilon) \tau \cdot f(L)=(1-L) \cdot b+L \cdot s
$$

Equations (2), (3), (4) and (6) give the aggregate resource constraint:

$$
(1-\varepsilon \cdot \tau) f(L)=w_{h}+L \cdot w_{l}+(1-L) \cdot b
$$

A fraction $\varepsilon \cdot \tau$ of output corresponds to tax collecting costs. Only a fraction $1-\varepsilon \cdot \tau$ of output $f(L)$ is split between high skilled, low skilled employed and low skilled unemployed workers.

\section{III.2 The policymaking process}

The policymaking process sets the levels of unemployment benefits $b$, of subsidy $s$, of tax rate $\tau$ and of low skilled gross wage $W_{l}$ (the minimum wage level) subject to some relevant constraints. I assume a "political objective" function of the form:

$$
P\left(v\left(w_{h}\right), L \cdot v\left(w_{l}\right)+(1-L) v(b)\right)
$$

$P(.,$.$) is increasing in high skilled workers' utility v\left(w_{h}\right)$ and in low skilled workers' expected utility $L \cdot v\left(w_{l}\right)+(1-L) v(b)$. Function $P(.,$.$) is also differentiable and weakly$ concave.

The policymaker considers the laissez faire to be unfair at the expense of low skilled worker. It is therefore assumed that, starting from the laissez faire, a marginal increase of low skilled workers' income trough fiscal transfer increases the political objective. From equation (6), a marginal increase of tax rate by $\Delta \tau$ implies at full employment a rise in subsidy by $(1-\varepsilon) f(1) \Delta \tau$. Hence, low skilled workers' income increases by $\left[(1-\varepsilon) f(1)-f^{\prime}(1)\right] \Delta \tau$ whereas high skilled workers's income decreases by

\footnotetext{
${ }^{3}$ The linear specification for this cost is just a simplifying assumption. Assuming instead a tax collecting cost of the form $\varepsilon \cdot \phi(\tau)$ with $\varepsilon \cdot \phi(\tau) \leq \tau$ and $\phi^{\prime}($.$) positive and bounded would lead to very similar results.$
} 
$-\left[f(1)-f^{\prime}(1)\right] \Delta \tau$. I hence assume that ${ }^{4}$ :

$$
P_{l}^{\prime} v^{\prime}\left(w_{l}^{0}\right)-P_{h}^{\prime} v^{\prime}\left(w_{h}^{0}\right)>\varepsilon \frac{f^{\prime}(1)}{f(1)-f^{\prime}(1)} P_{l}^{\prime} v^{\prime}\left(w_{l}^{0}\right)
$$

Representing the political process with a "blackbox" such as the maximization of (8) allows to consider very simply two economies that are identical in all aspects but the existence of Time Constitency constraint. The main restriction with this specification of the political objective is that employed and unemployed low skilled workers are equally considered by the policymaker. This is in contrast with Saint Paul's (2000) political insider theory. It can be supported by assuming that low skilled workers consider policies behind the veil of ignorance about their status on the labor market.

There is many possible microfondations for a political objective of the form (8) (see Persson and Tabellini (2000) for a complete survey). If the policymaker is the government, one can consider a vote on a selfish representative that choose policies behind the veil of ignorance (before knowing whether voters will be high or low skilled workers). The political objective then takes a linear form: $P(.,)=.p \cdot v\left(w_{h}\right)+(1-p)\left[L \cdot v\left(w_{l}\right)+(1-L) v(b)\right]$, where $p$ stands for the ex-ante (median) probability of becoming skilled. A probabilistic electoral competition framework à la Lindbeck and Weibull (1987) or a lobbying framework similar to Grossman and Helpman (1994) may also lead to such a linear specification of the political objective. A Nash Bargaining between a high and a low skilled specific union (or Lobby or Group Pressure) might be a more relevant framework for countries where social decisions are taken at the national level by negotiations between "social partners" (as in Germany or Nordic countries). If in case of disagreement, a huge social crisis emerges so that nothing is produced, the threat points reached by the negotiators then equal to $v(0)$. The generalized Nash criteria therefore writes: $P(.,)=.\left(v\left(w_{h}\right)-v(0)\right)^{\gamma}\left(L \cdot v\left(w_{l}\right)+(1-L) v(b)-v(0)\right)^{1-\gamma}$, with $0<\gamma<1$ denoting the high skilled workers' bargaining power.

\section{The political outcomes in the one-shot game}

Following, Kydland and Prescott (1977) or Barro and Gordon (1983), two policymaking processes are contrasted. First, under a Time Inconsistent (TI) process, the policymaker is the Stackelberg leader and chooses its policy taking into account labor demand functions. Second, under a Time Consistent (TC) process, firms are the Stackelberg leader and policymakers chooses its policy taking employment levels as given.

\footnotetext{
${ }^{4}$ For any variable $x, x^{0}$ denotes its laissez faire value.
} 


\section{IV.1 The Time Inconsistent case}

Under a TI process, the timing is:

1. The choice of policy by the policymaker.

2. The choice of employment by the representative firm.

3. High skilled gross wage clears the firm's budget constraint according to (2). Production and transfers occur.

The policymaker then perfectly integrates the consequences of its decisions on firm's labor demands. Solving the model backward, the policymaker maximizes $P(.,$.$) subject$ to labor demands (3) and (4) and the budget constraint (6):

$$
\begin{aligned}
& \max _{w_{l}, w_{h}, b, \tau, s, L} P\left(v\left(w_{h}\right), L \cdot v\left(w_{l}\right)+(1-L) v(b)\right) \\
& \text { s.t. }(3),(4),(6) w_{l} \geq b, L \leq 1 \text { and } s \geq 0
\end{aligned}
$$

We get the following proposition (see Appendix A.1 for the proof):

Proposition 1 If $\varepsilon<\varepsilon^{*}$, where

$$
\varepsilon^{*}=\min \left[\sigma(L) ; \frac{P_{l}^{0 \prime} v_{l}^{0 \prime}-P_{h}^{0 \prime} v_{h}^{0 \prime}}{P_{l}^{0 \prime} v_{l}^{0 \prime}} \cdot \frac{f(1)-f^{\prime}(1)}{f(1)}\right]
$$

the TI policy implies full employment $L=1$ and positive subsidy $s>0$.

The intuition for this result is the following. Assume by contradiction that there is some unemployment at the optimum. Then, it is perfectly insured. This is because a given amount of resources can be split without any distortion by changes in subsidy $s$ and benefit $b$ for given levels of tax rate $\tau$ and low skilled gross wage $W_{l}$ (thereby given levels of employment, output, tax collecting costs and high skilled workers' income).

Consider then a rise in employment subsidy $s$ and a decrease in low skilled gross wage $W_{l}$ such that low skilled after-tax wage $w_{l}$ remains unchanged. Assume the tax rate $\tau$ is adjusted so as to keep the budget balanced. Since unemployment is perfectly insured and low skilled after tax wage $w_{l}$ is unchanged, so is low skilled workers' expected utility. Hence, the consequence on the political objective $P($.$) depends only on the reaction on$ high skilled workers' income, that is, according to (7), on the total amount of resources to be shared $(1-\varepsilon \cdot \tau) f(L)$. On the one hand, the decrease in low skilled gross wage $W_{l}$ raises employment $L$, thereby gross output $f(L)$. This mechanism is stronger the higher the elasticity of substitution between high and low skilled labor $\sigma(L)$. On the other hand, 
the rise in subsidy $s$ raises ${ }^{5}$ tax rate $\tau$, thereby increasing tax collecting costs $\varepsilon \cdot \tau \cdot f(L)$. This mechanism is stronger the higher $\varepsilon$. Hence, when $\varepsilon$ is "sufficiently" small compared to $\sigma(L)$, the former effect dominates, implying that the political objective can be increased if full employment is not attained.

The inequality

$$
\varepsilon<\frac{P_{l}^{0 \prime} v_{l}^{0 \prime}-P_{h}^{0 \prime} v_{h}^{0 \prime}}{P_{l}^{0 \prime} v_{l}^{0 \prime}} \cdot \frac{f(1)-f^{\prime}(1)}{f(1)}
$$

is exactly equivalent to (9). It implies that the political pressure for redistribution is sufficiently high for the equilibrium redistribution to be in favor of low-skilled worker and at the expense of high skilled ones.

Is $\varepsilon<\sigma(L)$ empircally relevant? On the one hand, $\varepsilon$ is a parameter that is always lower than 1 , and that is probably much more closer to 0 than to 1 . On the other hand, estimating $\sigma$ is the topic of a very large empirical literature (see Hamermesh (1993)). The estimations are rather divergent, but converge to the conclusion of a value of $\sigma$ that is significantly positive, and that might be higher than 1 . So $\varepsilon<\sigma$ seems realistic, and so therefore does the inequality $\varepsilon<\varepsilon^{*}$.

\section{IV.2 The Time Consistent case}

Under TC process, the timing of decisions is ${ }^{6}$ :

1. The choice of employment by firms.

2. The choice of policy by the policymaker.

3. High skilled gross wage clears the firm's budget constraint according to (2). Production and transfers occur.

Solving the model backward, redistributive policies are chosen, given the employment level $L$, according to:

$$
\begin{array}{ll}
\max _{w_{l}, w_{h}, b, \tau, s} & P\left(v\left(w_{h}\right), L \cdot v\left(w_{l}\right)+(1-L) v(b)\right) \\
\text { given } L, & \text { s.t. }(6),(7), w_{l} \geq b \text { and } s \geq 0
\end{array}
$$

The policymaker takes the level of employment $L$ as given. Furthermore, she integrates the firm's budget constraint. According to equation (2), an increase of $d W_{l}$ in minimum

\footnotetext{
${ }^{5}$ Since employment $L$ increases, the total taxable income $f(L)$ is raised and unemployment benefits expenditures $(1-L) b$ are decreased. This pushes downwards the tax rate $\tau$. However, it turns out that one can neglect this "Laffer" effect to better understand the main mechanisms at work.

${ }^{6}$ The outcome would be the same if firms and policymaker act simultaneously, instead of the representative firm playing first. This is because each firm is atomistic, and hence neglects the influence of its action on the policy chosen. Barro and Gordon (1983) point a similar remark for their positive inflation theory.
} 
wage decreases the high skilled gross wage by $d W_{h}=-L \cdot d W_{l}$. Rewriting (2) in terms of after tax wages leads to (7). One then gets the following proposition (see Appendix A.2 for the proof):

Proposition 2 The TC policy implements no specific subsidy to low skilled workers $s=0$ and implies unemployment $L<1$.

Once firms have set their labor demand, the drawbacks of rising low skilled gross wage in terms of lower employment is no longer internalized. Consider a rise in low skilled gross wage $W_{l}$ and a decrease in employment subsidy $s$ such that low skilled after-tax wage $w_{l}$ remains unchanged. Then, output is no longer decreased since employment has been already set. Taxable income and unemployment benefits expenditures are unchanged. Conversely, expenditures on subsidy $s$ decreases. So the tax rate $\tau$ decreases and thereby tax collecting costs. Furthermore, during stage 1, firms perfectly anticipate that low skilled gross wage will be at a higher value than at laissez faire. Firms thus set their labor demand below the full employment levels and unemployment appears.

To conclude this section, one can use a benchmark specification of the model. Let the political objective be linear $P=p \cdot v\left(w_{h}\right)+(1-p)\left[L \cdot v\left(w_{l}\right)+(1-L) v(b)\right]$, the utility function being CRRA $v(c)=c^{1-\lambda} /(1-\lambda)$ and the production function being CES $Y=\left[\alpha \cdot H^{1-\frac{1}{\sigma}}+(1-\alpha) L^{1-\frac{1}{\sigma}}\right]^{\frac{\sigma}{\sigma-1}}$. With such specifications, a rise in $p$ reflects a political shock towards less redistributive taste whereas a rise in $\alpha$ reflects a skill-biased technological change. The equilibrium level of employment under TC is then (see Appendix A.2):

$$
L=\left(\frac{1-\alpha}{\alpha}\right)^{\sigma} \cdot\left(\frac{p}{1-p}\right)^{\frac{\sigma}{\lambda}}
$$

This leads to the following proposition.

Proposition 3 Under the benchmark specification, in a TC environment, employment decreases with a skill-biased technological change and increases with skilled workers' political influence. Employment and wage inequality are therefore positively correlated

Conversely, under TI environment, neither technological shocks nor political shocks change the employment level. Employment and wage inequality are therefore not correlated.

This proposition characterizes another crucial difference between TI and TC economies. They differ not only by the level of employment, but also by the reactions of employment to different shocks. The intuition is that under TI environment, full employment remains so shocks do not change the employment level. They only change the amount of redistribution. Conversely, under a TC environment, their is no incentive to implement subsidy $s$, 
so employment is an increasing function of the relative net wage $w_{h} / w_{l}$. Moreover, with the benchmark specification, this relative wage appears to be an increasing function of skilled workers' political power $p$ only. A political shock therefore changes the relative net wage and thereby the employment level, whereas a skill-biased technological shock leaves unchanged the relative net wage and thereby decreases the employment level.

The setting used is rather simplistic and neglects many important features of real labor markets. If these features were integrated, technological or political shock would very likely affect employment levels even under TC process. Proposition 3 remains important, provide we consider it in a weaker sense. Compared to a TI environment, there are additional channels in TC environments that make employment decreasing with a skill biased technological change and with political taste for redistribution. Hence, the correlation between employment and wage inequality is higher (more positive).

\section{The political outcomes in the dynamical game}

The preceding section highlights that policymakers are likely to underestimate the drawbacks of wage regulation when the timing of policymaking and wage setting processes is not adequate. However, what the origins of such bad timings are remains an open question. As already mentionned, I propose two theoretical explanations. First, policymakers may be available to commit only over a short term horizon. Over this horizon, the relevant elasticity of the labor demand is smaller than the long-run elasticity because of adjustment costs and thereby the underestimation of the drawbacks of wage regulation. This is the "short-term argument". Second, policymakers may be unable to make any binding commitment over their policies, because they lask credibility. Thus, firms believe that redistribution will occur through wage regulation instead of transfers. They reduce their labor demand independently of policymakers' announces. Policymakers then observe their inability to influence firms' expectations over the wage structure, so they believe they are unable to change employment levels. Hence, they choose the redistributive policy ignoring its impact on employment. This is the "lack of credibility argument". In this section I propose a dynamic extension of the model with adjustment costs to evaluate the relevance of these arguments.

Following Cohen and Michel (1988), one can contrast three different timings in a dynamical setting, for political and economical decisions. First, the policymakers can decide once for all the time every policy for every remaining period. This Time Inconsistent case gives a normative benchmark. Second, at time $t$, the policymaker first sets her policy before firms take their decisions. This "Time Consistent with instantaneous precommitment" case is adequate to evaluate the "short term argument". The policymaker 
does then integrate the consequence of her current choice on the labor demand. But this integration is only partial by the existence of adjustment costs that makes current employment depending also on past and future policies. Finally, policymakers may choose her policy after firms set their labor demand. Then, whatever the current redistributive policy is, it does not influence firms' expectation for the current level of gross wage, so it does not influence the current employment level. This formalizes the "lack of credibility argument".

\section{V.1 The dynamical framework}

The model is now a discrete time framework with infinite but discounted time horizon. There is neither capital, nor financial markets nor savings. For ease of computation, adjustment costs are assumed to be quadratic and of the form $\frac{\gamma}{2}\left(L_{t}-L_{t-1}\right)^{2}$. The representative firm's value at date $t$ solves the Bellman equation:

$$
V\left(L_{t-1}\right)=\max _{L_{t}}\left\{f\left(L_{t}\right)-W_{t}^{L} \cdot L_{t}-\frac{\gamma}{2}\left(L_{t}-L_{t-1}\right)^{2}-W_{t}^{H}+\delta \cdot V\left(L_{t}\right)\right\}
$$

where $\delta<1$ denotes the exogenous discount factor. Solving this program leads to:

$$
W_{t}^{L}=f^{\prime}\left(L_{t}\right)+\delta \cdot \gamma\left(L_{t+1}-L_{t}\right)+\gamma\left(L_{t-1}-L_{t}\right)
$$

Current demand for labor is a function of past employment, current (low-skilled) gross wage, but also expected future employment. Hence, current demand for labor crucially depends on the expected futures policies. Skilled workers are assumed to own the representative firm, so adjustment costs decrease high skilled workers' gross income. Hence:

$$
W_{t}^{H}=f\left(L_{t}\right)-W_{t}^{L} \cdot L_{t}-\frac{\gamma}{2}\left(L_{t}-L_{t-1}\right)^{2}
$$

Equations (3), (4) (6) and (7) respectively become:

$$
\begin{aligned}
\left(1-\tau_{t}\right)\left[f\left(L_{t}\right)-W_{t}^{L} \cdot L_{t}-\frac{\gamma}{2}\left(L_{t}-L_{t-1}\right)^{2}\right] & =w_{t}^{h} \\
\left(1-\tau_{t}\right) W_{t}^{L}+s_{t} & =w_{t}^{l} \\
(1-\varepsilon) \tau_{t}\left[f\left(L_{t}\right)-\frac{\gamma}{2}\left(L_{t}-L_{t-1}\right)^{2}\right] & =\left(1-L_{t}\right) b_{t}+L_{t} \cdot s_{t} \\
\left(1-\varepsilon \cdot \tau_{t}\right)\left[f\left(L_{t}\right)-\frac{\gamma}{2}\left(L_{t}-L_{t-1}\right)^{2}\right] & =w_{t}^{h}+L_{t} \cdot w_{t}^{l}+\left(1-L_{t}\right) b_{t}
\end{aligned}
$$

I assume that at each date, low-skilled workers are uniformly randomized between employment and unemployment according to an i.i.d. process. I also consider that the political objective $P(.,$.$) is linear. The policymaker's lifetime utility is therefore:$

$$
W_{t}=\sum_{k=0}^{+\infty} \delta^{k} \cdot P\left\{v\left(w_{h, t+k}\right), L_{t+k} \cdot v\left(w_{l, t+k}\right)+\left(1-L_{t+k}\right) v\left(b_{t+k}\right)\right\}
$$


In particular I assume the same discount rate for firms and for the policymaker. This is because most of micro-foundation of the political objective implies the political objective to be an aggregator of economics agents' welfare. Hence, there is no reason why the discount rate incorporated in this aggregator should be different. Put differently, a short lived politician is not a politician that "under-prefers" future compared to voters for any exogenously different preference. It is only a politician that can act during a short period.

\section{V.2 The Time Inconsistent Case}

In the Time Inconsistent case, a commitment at date 0 over all present and future policies is assumed to be credible and binding. This very strong assumption allows policymakers to choose once, at time 0 , all policies for any time $t \geq 0$. The policymaker's choice hence solves:

$$
\begin{aligned}
& \max _{\left\{L_{t}, s_{t}, \tau_{t}, W_{t}^{L}, w_{l, t}, w_{h, t}, b_{t}\right\}_{t \geq 0}} \sum_{t=0}^{+\infty} \delta^{t} P\left\{v\left(w_{h, t}\right), L_{t} \cdot v\left(w_{l, t}\right)+\left(1-L_{t}\right) v\left(b_{t}\right)\right\} \\
& \text { s.t. : } \quad \forall t \quad(14),(16),(17),(18), \quad 0 \leq s_{t}, \tau_{t} \quad L_{t} \leq 1 \quad \text { given : } L_{-1}
\end{aligned}
$$

Characterizing a steady-state equilibrium under infinitely long credible binding commitment is equivalent to solving the static optimal rule (see Appendix B.1 for a formal proof). Hence, if $\varepsilon<\sigma$, proposition 1 could be applied and insures that the only steadystate in this case yields full employment $L=1$ and redistribution by fiscal means only $s, \tau>0$.

\section{V.3 The short-term case}

I consider now the case where policymaker makes a binding commitment over the current policy. In this case, the sequence of decisions in period $t$ is:

1. Policymaker chooses its policy $\left\{W_{t}^{L}, \tau_{t}, s_{t}, b_{t}\right\}$ for period $t$.

2. Firm chooses its labor demand $L_{t}$, given $L_{t-1}$, current and expected future policies, according to (14).

3. High skilled wage $W_{t}^{H}$ clears firms' budget constraint according to (15). Transfers occur.

If the time horizon was finite, the equilibrium would require subgame Nash perfection. In the present infinite time-horizon, any maximizing problem is defined recursively, at any point in time. Hence, following Krusell et alii (1997), I describe firm's and policymaker's behaviors by state-contingent time-invariant Markovian strategies. These strategies depend only on the value of the relevant state variable, that is on $L_{t-1}$. I denote 
these strategies respectively by $L_{t}=\Phi^{\mathrm{c}}\left(L_{t-1}, W_{t}^{L}\right)$ for firms and by $W_{t}^{L}=\pi^{\mathrm{c}}\left(L_{t-1}\right)$ for the policymaker. Along the equilibrium path, the aggregate dynamics is then given by $L_{t}=\theta^{\mathrm{c}}\left(L_{t-1}\right) \equiv \Phi^{\mathrm{c}}\left(L_{t-1}, \pi^{\mathrm{c}}\left(L_{t-1}\right)\right)$.

Subgame perfection implies that firm's strategy solves its profit maximizing program, given that future dynamics of employment is described by the equilibrium dynamics $\theta^{\mathrm{c}}($.$) .$ From firm's Euler equation (14), $L_{t}=\Phi^{\mathrm{c}}\left(L_{t-1}, W_{t}^{L}\right)$ solves:

$$
W_{t}^{L}=f^{\prime}\left(L_{t}\right)+\delta \cdot \gamma\left(\theta^{\mathrm{c}}\left(L_{t}\right)-L_{t}\right)+\gamma\left(L_{t-1}-L_{t}\right)
$$

Similarly, function $\pi^{\mathrm{c}}($.$) solves the period t$ policymaker's program:

$$
\begin{aligned}
\Omega\left(L_{t-1}\right)= & \max _{L_{t}, s_{t}, \tau_{t}, W_{t}^{L}, w_{l, t}, w_{h, t}, b_{t}} P\left(v\left(w_{h, t}\right), L_{t} v\left(w_{l, t}\right)+\left(1-L_{t}\right) v\left(b_{t}\right)\right)+\delta \cdot \Omega\left(L_{t}\right) \\
\text { s.t. : } & L_{t}=\Phi^{\mathrm{c}}\left(L_{t-1}, W_{t}^{L}\right),(16),(17),(18), \quad 0 \leq s_{t}, \tau_{t} \quad L_{t} \leq 1 \\
\text { given : } & L_{t-1} \quad \text { and } \quad \forall k \geq 1 \quad L_{t+k}=\theta^{\mathrm{c}}\left(L_{t+k-1}\right)
\end{aligned}
$$

A fixed point between three functional equations therefore defines the political-economic equilibrium. The policymaker's behavior $W_{t}^{L}=\pi^{\mathrm{c}}\left(L_{t-1}\right)$ depends on how firm currently reacts to a current deviation to the equilibrium policy. This reaction is described by $L_{t}=\Phi^{\mathrm{c}}\left(L_{t-1}, W_{t}^{L}\right)$. But to compute this reaction, one needs to know what will be future policies, or equivalently, what will be the future dynamics of employment that is $L_{t+1}=\theta^{\mathrm{c}}\left(L_{t}\right)=\Phi^{\mathrm{c}}\left(L_{t-1}, \pi\left(L_{t-1}\right)\right)$. So one need to now function $\pi^{\mathrm{c}}($.$) . A sufficient$ condition for a stable steady state equilibrium necessarily yielding full employment and positive subsidy can be derived (see Appendix B.2).

Proposition 4 If $\varepsilon<\varepsilon^{c}$ where

$$
\varepsilon^{c}=\min _{L}\left[\frac{\sigma(L)}{1-\frac{\gamma(1+\delta)}{f^{\prime \prime}(L)}}, \frac{P_{l}^{0 \prime} v_{l}^{0 \prime}-P_{h}^{0 \prime} v_{h}^{0 \prime}}{P_{l}^{0 \prime} v_{l}^{0 \prime}} \cdot \frac{f(1)-f^{\prime}(1)}{f(1)}\right]
$$

the unique stable steady-state equilibrium yields full employment $L=1$ and positive subsidy $s>0$.

Condition (23) is more restrictive than condition (11). This is because adjustment costs make the labor demand dynamic. Hence, a current change in the low skilled gross wage has a smaller effect on current employment than a permanent change has on steady-state employment. In the static framework, only the latter was taken into account. Now, the former is also considered by a short-lived policymaker. A short-lived policymaker hence underestimates the gain of decreasing low-skilled gross wage (by increasing subsidy) in terms of higher employment and output. This is the "short-term argument". It should 
be noticed that the higher adjustment costs $\gamma$ are, the larger is the underestimation of labor demand effects by a short lived policymaker, so the higher should be the elasticity of substitution $\sigma$ or the lower should be tax collecting costs $\varepsilon$ for a short-lived policymaker to choose policies that keeps full employment.

To what extent $\varepsilon^{*}$ and $\varepsilon^{c}$ are quantitatively different? To answer this question, I compute $\varepsilon^{\mathrm{c}}$ as a function of adjustment costs $\gamma$ for different values of $\sigma^{7}$. To give a magnitude to $\gamma$, I express it as a function of the half-life adjustment $d$ of the labor demand after an idiosyncratic shock on wage $\operatorname{cost}^{8}$. Figure 1 displays $\varepsilon^{\mathrm{c}}$ as a function of $d$ for different values of $\sigma$, (namely $\sigma=0.4,0.8,1.2$ and 1.6). In the four figures, for small enough values of $d, \varepsilon^{\mathrm{c}}$ is horizontal and is equal to $\frac{P_{l}^{0 \prime} v_{l}^{0 \prime}-P_{h}^{0 \prime} v_{h}^{0 \prime}}{P_{l}^{0 \prime} v_{l}^{0 \prime}} \cdot \frac{f(1)-f^{\prime}(1)}{f(1)}$ which is the highest value of the tax collecting cost consistent with assumption (9). Hence, for plausible values of $\sigma$, one needs a half-life adjustment of more than half a year for $\varepsilon^{c}$ to be smaller than $\varepsilon^{*}$. Moreover, half-life adjustment of labor demand in US is between one and two quarters (see Hamermesh (1993)). In Europe, half-life adjustment might be higher, but probably shorter than one year. In France,

Bresson et alii (1996) finds that estimates of adjustment costs are much lower for low skilled labor demand or for high skilled labor demand than for aggregate data. For low skilled workers, the median delay is arround 0.5 year whereas for skilled workers it is around 1.1 year. The cases for $\varepsilon^{c}<\varepsilon^{*}$ only appear for very low values of $\sigma$ and very slow adjustments of the labor demand. Hence, a short term policmaking process is likely to give a similar outcome than a dynamic TI one with full employment and redisitribution though fiscal transfers only $s>0$. This suggests that the "short-term argument" does not appear very convincing for explaining the overuse of wage rigidities schemes.

\section{V.4 The lack of credibility}

I finally consider the case where policymaker are unable to make any binding commitment over the current policy. In this case, the sequence of decisions in period $t$ is:

1. Firm chooses its labor demand $L_{t}$, given $L_{t-1}$, current and expected future policies, according to (14).

\footnotetext{
${ }^{7}$ I use the benchmark specification with $\lambda=1$, and $p$ and $\alpha$ such that one gets $L=0.9$ and $w_{h} / w_{l}=2$ at the static TC equilibrium. I take $r=0.05$ for the discount rate. The Mathematica 4.0 program is available on my homepage.

${ }^{8}$ This means that $\gamma$ is such that $\rho=(1 / 2)^{1 / d}$ is the stable root of the characteristic polynomial of the linearization around the steady state of equation (14) that is

$$
\delta \gamma \cdot \rho^{2}+\left(f^{\prime \prime}(1)-\gamma(1+\delta)\right) \rho+\gamma=0
$$

where $d$ stands for the half-life of adjustment of labor demand.

After an indiosyncrasic shock, the dynamics of employment is well approximate by $L_{t}=\rho^{t} L_{0}$ and the half life adjustment $d$ then solves $\ln \rho^{d}=\ln 1 / 2$ (see Cahuc and Zylberberg (2004)).
} 
Figure 1: $\varepsilon^{c}$ as a function of adjustment costs

2. Policymaker chooses its policy $\left\{W_{t}^{L}, \tau_{t}, s_{t}, b_{t}\right\}$ for period $t$.

3. High skilled wage $W_{t}^{H}$ clears firms' budget constraint according to (15). Transfers occur.

In this case, firm's labor demand is a function of the level $W_{t}^{L, e}$ of low-skilled gross wage that is expected for the current period and of past employment, according to $L_{t}=\Phi^{\mathrm{n}}\left(L_{t-1}, W_{t}^{L, e}\right)$. Moreover, to form its expectations, the representative firm uses the same information set as the policymaker does to select policies, so firm expects $W_{t}^{L, e}=$ $\pi^{\mathrm{n}}\left(L_{t-1}\right)$. Consequently, the current level of employment is a function of past employment only, through $L_{t}=\theta^{\mathrm{n}}\left(L_{t-1}\right) \equiv \Phi^{\mathrm{n}}\left(L_{t-1}, \pi^{\mathrm{n}}\left(L_{t-1}\right)\right)$. Hence, when policymaker takes its decisions, she considers that a deviation at time $t$ from the policy $\pi^{\mathrm{n}}\left(L_{t-1}\right)$ has no effect on the level of employment. This is because labor demand has been set as a function of ex-ante expected (and not ex-post effective) low-skilled gross wage. She hence considers that a rise in low skilled gross wage $d W_{l, t}$ does not change the level of employment but implies a decrease of high skilled gross wage of $d W_{h, t}=-L_{t} \cdot W_{l, t}$. Eliminating $W_{l, t}$ and $W_{h, t}$ in (16) and (17), equation (19) expresses in terms of after tax income this causality. The policymaker's program during period $t$ is therefore:

$$
\begin{aligned}
\Omega\left(L_{t-1}\right)= & \max _{s_{t}, \tau_{t}, w_{l, t}, w_{h, t}, b_{t}} P\left(v\left(w_{h, t}\right), L_{t} v\left(w_{l, t}\right)+\left(1-L_{t}\right) v\left(b_{t}\right)\right)+\delta \cdot \Omega\left(L_{t}\right) \\
\text { s.t. : } & (18),(19) \quad 0 \leq s_{t}, \tau_{t} \\
\text { given : } & \forall k \geq 0 \quad L_{t+k}=\theta^{\mathrm{n}}\left(L_{t+k-1}\right)
\end{aligned}
$$


This program is actually completely static, since the dynamics is entirely exogenous to the policymaker. Hence her choice is similar to the static case with no binding commitment (see Appendix B.3 for a formal proof of this claim). Once employment is set, the policymaker's best policy consists in redistributing income without any subsidy by wage rigidity means only. Firm expecting such behavior reduces her labor demand and the steady-state yields positive unemployment ${ }^{9}$.

The property that policymaker's action has no influence on the employment dynamics is very counter-intuitive, because even if the policymaker knows that labor demand is elastic, she cannot increase employment. This is because lack of credibility makes employment level depending on expected policies $W_{t}^{L, e}=\pi^{\mathrm{n}}\left(L_{t-1}\right)$ and on effectively chosen ones. Hence, any deviation of the policymakers from the expected policy $W_{t}^{L} \neq \pi^{\mathrm{n}}\left(L_{t-1}\right)$ has no effect onto employment levels. Policymaker has then no incentives for redistributing income efficiently, although she perfectly knows her policy is ex-ante inefficient.

There is here kind of prisoner dilemma. Firms observe a rather high level of gross wage. So they believe the policymaker only tries to reduce tax collecting cost without any concerns for wage moderation. Hence, they have a rather low labor demand, independently of policymaker's announces. Policymaker observes that, whatever she claims about her concern for labor cost moderation, firms do not increase their labor demand. So she believes she cannot increase employment by decreasing the gross wage. Hence the only distortion costs she considers are tax collecting costs and she use wage regulation tools only. This behaviour in turn confirms firms' beliefs. Here, neither an ideological bias (as advocated by Piketty (1999)), nor a short-term argument makes the policymaker choosing inefficient redistributive policies but only the lack of short-term credibility.

\section{Empirical investigation}

In this section, I ask empirically what institutions are more likely to induce time consistency constraint in the policymaking process over redistributive policies. Put differently, I ask which institutional environment favours the "unemployment bias". The problem is that institutions influence employment rates by many other mechanisms then the Time Consistency mechanism I stress in this article. Hence, I can not deduce whether an institution increase time consistency constraint only from its direct effect on employment levels. However, Proposition 3 gives a theoretical prediction that is specific to the Time Consistency mechanism. In a TC environment, employment rates is "more" increasing with respect to change in wage inequality then in an environment without Time Consistency

\footnotetext{
${ }^{9}$ This argument remains if adjustement costs over policy choices (in particular over $W_{t}^{L}$ ) were introduced.
} 
constraints.

I therefore use a panel datasets of OECD countries (indexed by $i$ ) over the period $t=1962-1995$ (see Appendix C for further details and my homepage). I regress employment rates $E P O P_{i, t}$ on an inequality measure $I N E Q_{i, t}$, measures of some time varying institutions Instit $i_{i, t}^{k}$ and cross effect of institutions times inequality Instit $t_{i, t}^{k} \times I N E Q_{i, t}$. To control for over standard macroeconomic determinants of unemployment, I include the acceleration of money supply $\Delta^{2} M_{i, t}^{s}$, the real interest rate $R I R L_{i, t}$ and the real terms of trade $T T S_{i, t}$ as additional explanatory variables. Finally, country specific effects and Time dummies are added ${ }^{10}$. The typical regression is therefore of the form:

$$
\begin{aligned}
\operatorname{EPOP}_{i, t}= & c+\alpha \cdot I N E Q_{i, t}+\sum_{k} \beta_{k} \cdot \text { Instit }_{i, t}+\sum_{k} \gamma_{k} \cdot \text { Instit }_{i, t} \times I N E Q_{i, t} \\
& +\delta_{1} \cdot \Delta^{2} M_{i, t}^{s}+\delta_{2} \cdot R I R L_{i, t}+\delta_{3} \cdot T T S_{i, t}+\varepsilon_{i}+\phi_{t}+v_{i, t}
\end{aligned}
$$

According to proposition 3, a significantly positive (resp. negative) estimate for $\gamma_{k}$ would suggest the $k^{\text {th }}$ institution worsens (relaxes) time consistency constraints. Following the discussion in the preceding section, two kinds of institutions are of a particular interest. First, I expect more coordinated wage setting process $C O_{i, t}$ to decrease the slope between employment and inequality. This conjecture follows the "lack of credibility argument" and the suspicion that more coordination leads to more credibility in determining redistributive policies. Hence $\gamma_{c o}<0$ is expected. Second, I expect higher employment protection $E P_{i, t}$ to increase the slope between employment and inequality since higher employment protection should lead to higher adjustment costs and to worsens policy choices according to the "short-termism argument". Hence $\gamma_{E P}>0$ is expected.

I first use the $P 50 / P 10$ ratio as a measure of income inequality. The baseline estimates for $\alpha$ and $\gamma_{k}$ parameters are then given in Table 1, equations 1 to 4 . First in every regressions, employment rates appear to be significantly increasing in wage inequality. I then introduce in regression (2) two institutions, namely a measure of coordination of wage setting and of employment protection. As expected, higher coordination makes employment rates less decreasing to income inequality, but the estimate is not statistically significant. Conversely, stricter employment protection unexpectedly decreases the slope of employment rate with respect to inequality. Furthermore, this effect turns to be significant. I then introduce in equation (3) and (4) only one institution at a time to prevent from co-linearity of explanatory variables. The estimates keep the same sign, but their

\footnotetext{
${ }^{10}$ In particular, country specific effect captures unobserved institutional heterogeneity between countries. However, I have compared my within estimates to GLS ones. Both methods lead to similar conclusions. The introduction of time dummies is an imperfect way to capture the existence of trends in the different variables involved in equation (25). I have compared my estimates with Time dummies with estimates using only linear time trends. Once again, both methods lead to similar conclusions.
} 
statistical significance increase. This first empirical exercise tends to confirm the "lack of credibility argument": higher wage coordination increase the credibility of the policymaking process thereby decreasing the slope of employment rates with respect to income inequality. However, that higher employment protection does not have the expected effect seems to confirm the implausibility of the "short-term" argument.

These first estimations are potentially biased by the following simultaneous bias. According to the theoretical model, inequality and employment are determined simultaneously as functions of the political pressure for redistribution. However, in estimating equation such as (25), not only inequality $I N E Q_{i, t}$ is endogenous but also the cross variables Instit $_{i, t} \times I N E Q_{i, t}$. I therefore choose to base my empirical detection of TC versus TI environments on a slightly different theoretical prediction. According to proposition 3, employment rates are more decreasing with a rise of the political pressure for redistribution. I use data on political votes to compute the difference between votes for left and right parties. I then build a trend variable $T R E N D S W A^{11}$ which, for each country accumulates over time the difference in political votes between left and right. TRENDSWA is a rather good proxy for the political pressure for redistribution. TRENDSWA is variable that is probably more exogenous than $P 50 / P 10$ Furthermore, TRENDSWA appear to explain rather well the $P 50 / P 10$ ratio.

$$
P 50 / P 10_{i, t}=\underset{20.2^{* * *}}{0.034 T E N D S W} A_{i, t}+v_{i, t} \quad R^{2}=63.5 \%
$$

Table 1, equations 5 to 8 replicates the regressions displayed by equations 1-4 using TRENDSWA instead of $P 50 / P 10$ ratio. The results are rather very consistent with the first ones. In particular, they tend to confirm the "lack of credibility" argument because estimates of $\gamma_{C O}$ is negative when significant, and they tend to reject the "short term" argument since estimate of $\gamma_{E P}$ does not have the sign expected by the theory.

The next exercise wishes to contest the following critics. The influence of coordination over the credibility of the policymaking process is probably much more persistent then the time-varying measure of coordination given by the datasets. Similarly, the influence of employment protection over the short-term elasticity of labor demand must be much more persistent then the time-varying measure of employment protection. Facing this critic, I replace time-varying institutional measures by their country-specific averages. The results are displayed in Table 1, equations 9 to 12. Again, the estimates are consistent with the idea that higher coordination may improve the credibility of the wage setting process. However, the results with respect to employment protection are slightly more consistent

\footnotetext{
${ }^{11}$ See equation (26) in Appendix C. Actually, I re-scale this variable by a scale factor -0.01 . The negative sign has been so that a rising persistence of votes for right parties has a similar effect as a rise of $P 50 / P 10$.
} 
with the short term argument since estimates of $\gamma_{E P}$ are either significantly positive (as expected) in regression (10) or non siginificant in regression (12).

Finally, I compare equations (1) to (4) to similar regression with the standardized unemployment instead of employment rates as the explanatory variable. Different arguments in favor of one or the other as the relevant measure of non-employment exist. On the one hand, the employment rate accounts for different types of hidden unemployment through inactivity such as discouraged unemployment. On the other hand, employment rates also account for non-economic determinants of activity, which is not the case for standardized unemployment rates. According to the theoretical results, I expect unemployment to be decreasing in inequality; according to the lack of credibility argument $\alpha<0$, I expect higher coordination to weaken this correlation $\gamma_{C O}>0$; according to the short term argument I expect employment protection to reinforce this correlation $\gamma_{E P}<0$. The results are displayed in Table 1, equations (13) to (16). Once again, the estimates are consistent with the expected signs for $\alpha$ and $\gamma_{C O}$, but contradict the theory concerning the predictions for $\gamma_{E P}$. This confirms the feeling that Time consistency constraints are essentially due to lack of credibility and not due a too short-term horizon for policymakers.

\section{Concluding remarks}

In this paper, I explore the consequences of the lack of credibility over redistributive policies targeted on low-skilled workers. If policymakers cannot credibly make binding commitments, the representative firm adjusts its labor demand as a function of the ex-ante expected policies, so the policymaker's behavior has no influence on the level of employment. The policy chosen uses only wage rigidity tools so as to prevent fiscal diversion. Firms expects such policy and therefore reduces their labor demand. Conversely, the optimal rule under binding commitment redistributes income through fiscal transfers only and achieves redistributive goals more efficiently. This result remains for plausible values of parameters in a dynamic framework with adjustment cost and short-term credibility. Empirical evidence tends to confirm this prediction. It seems that in countries where social partners are highly coordinated, employment rates respond less to technological shocks and react differently to political shocks. Hence, policymaking processes in redistributive policies should be reformed towards more transparent and binding agreements between governments and social partners.

The analysis could be extended. In particular, the integration of flows in the labor market, would allow a better understanding of the connections between the policymaking 


\begin{tabular}{|c|c|c|c|c|}
\hline & & $\begin{array}{c}\text { Inequality } \\
I N E Q \\
\alpha\end{array}$ & $\begin{array}{c}\text { Coordination } \\
I N E Q \times C O \\
\gamma_{C O}\end{array}$ & $\begin{array}{c}\text { Employment Protection } \\
I N E Q \times E P \\
\gamma_{E P}\end{array}$ \\
\hline (1) & \multirow{4}{*}{$\begin{array}{c}P 50 / P 10_{i, t} \\
E P O P_{i, t}\end{array}$} & $\begin{array}{c}24.9 \\
6.9 * * *\end{array}$ & - & - \\
\hline$(2)$ & & $\begin{array}{l}47.2 \\
5.5^{* * *}\end{array}$ & $\begin{array}{l}-7.0 \\
-1.1\end{array}$ & $\begin{array}{l}-18.9 \\
-2.3^{* *}\end{array}$ \\
\hline$(3)$ & & $\begin{array}{c}50.2 \\
5.9^{* * *}\end{array}$ & $\begin{array}{l}-15.7 \\
-3.3^{* * *}\end{array}$ & - \\
\hline$(4)$ & & $\begin{array}{l}39.2 \\
7.8^{* * *}\end{array}$ & - & $\begin{array}{l}-23.9 \\
-4.0^{* * *}\end{array}$ \\
\hline$(5)$ & \multirow{4}{*}{$\begin{array}{c}\text { TRENDSW } A_{i, t} \\
\operatorname{EPOP}_{i, t}\end{array}$} & $\begin{array}{l}0.94 \\
6.4^{* * *}\end{array}$ & - & - \\
\hline$(6)$ & & $\begin{array}{l}1.48 \\
5.4^{* * *}\end{array}$ & $\begin{array}{c}0.03 \\
0.2\end{array}$ & $\begin{array}{l}-1.24 \\
-3.75^{* * *}\end{array}$ \\
\hline$(7)$ & & $\begin{array}{l}1.64 \\
5.9^{* * * *}\end{array}$ & $\begin{array}{c}-0.51 \\
-2.95^{* * *}\end{array}$ & - \\
\hline$(8)$ & & $\begin{array}{l}1.51 \\
8.2^{* * *}\end{array}$ & - & $\begin{array}{r}-1.2 \\
-4.7^{* * *} \\
\end{array}$ \\
\hline$(9)$ & \multirow{4}{*}{$\begin{array}{c}P 50 / P 10_{i, .} \\
E P O P_{i, t}\end{array}$} & $\begin{array}{c}24.9 \\
6.9^{* * *}\end{array}$ & - & - \\
\hline (10) & & $\begin{array}{l}52.9 \\
4.3^{* * *}\end{array}$ & $\begin{array}{l}-27.1 \\
-2.4^{* *}\end{array}$ & $\begin{array}{l}23.7 \\
1.9^{*} \\
\end{array}$ \\
\hline (11) & & $\begin{array}{c}39.6 \\
3.9^{* * *}\end{array}$ & $\begin{array}{l}-9.1 \\
-1.5 \\
\end{array}$ & - \\
\hline (12) & & $\begin{array}{r}26.4 \\
4.6^{* * *} \\
\end{array}$ & - & $\begin{array}{l}-2.3 \\
-0.3^{* *} \\
\end{array}$ \\
\hline (13) & \multirow{4}{*}{$\begin{array}{c}P 50 / P 10_{i, t} \\
U R_{i, t}\end{array}$} & $\begin{array}{l}-13.65 \\
-5.8^{* * *}\end{array}$ & - & - \\
\hline (14) & & $\begin{array}{l}-28.1 \\
-5.0^{* * *}\end{array}$ & $\begin{array}{l}7.3 \\
1.7^{*}\end{array}$ & $\begin{array}{l}3.7 \\
0.7\end{array}$ \\
\hline (15) & & $\begin{array}{l}-29.0 \\
-5.3^{* * *}\end{array}$ & $\begin{array}{c}9.3 \\
3.0^{* * *}\end{array}$ & - \\
\hline (16) & & $\begin{array}{l}-20.4 \\
-6.1^{* * *} \\
\end{array}$ & - & $\begin{array}{r}10.5 \\
2.7 * * * \\
\end{array}$ \\
\hline
\end{tabular}

Table 1: Empirical results

$\mathrm{T}$ student statistics are reported below

$*, * *$ and $* * *$ respectively stands for significance at $10 \%, 5 \%$ and $1 \%$ 
process of redistributive policies on the one hand, and labor market flows rigidities such as firing costs on the other hand. This is on my research agenda.

\section{A The static model}

\section{A.1 The Time Inconsistent case}

Policymaker solves program (10). It hence maximizes $\mathbb{P}(L, \tau, s)$ where:

$$
\begin{aligned}
\mathbb{P}(L, \tau, s) & \equiv P\left\{v\left[(1-\tau)\left(f(L)-L \cdot f^{\prime}(L)\right)\right],\right. \\
& \left.L \cdot v\left[(1-\tau) f^{\prime}(L)+s\right]+(1-L) v\left[\frac{(1-\varepsilon) \tau \cdot f(L)-L}{1-L}\right]\right\}
\end{aligned}
$$

subject to $L \leq 1, \tau \geq 0, s \geq 0$ and $w_{l} \geq b$. Partial derivatives of $\mathbb{P}(., .,$.$) are:$

$$
\begin{aligned}
& \mathbb{P}_{s}^{\prime}=L \cdot P_{l}^{\prime}\left(v^{\prime}\left(w_{l}\right)-v^{\prime}(b)\right) \\
& \mathbb{P}_{\tau}^{\prime}=P_{l}^{\prime} v^{\prime}(b)(1-\varepsilon) f(L)-P_{h}^{\prime} v^{\prime}\left(w_{h}\right)\left(f(L)-L \cdot f^{\prime}(L)\right)-P_{l}^{\prime} v^{\prime}\left(w_{l}\right) \cdot L \cdot f^{\prime}(L) \\
& \mathbb{P}_{L}^{\prime}=P_{l}^{\prime}\left(v\left(w_{l}\right)-v(b)\right)+\left(P_{l}^{\prime} v^{\prime}\left(w_{l}\right)-P_{h}^{\prime} v^{\prime}\left(w_{h}\right)\right)(1-\tau) L \cdot f^{\prime \prime}(L)+P_{l}^{\prime} v^{\prime}(b)\left[(1-\varepsilon) \tau f^{\prime}(L)-s+b\right]
\end{aligned}
$$

Consider the necessary conditions for the solution of program (10) without the constraints $s, \tau \geq 0$. One gets $\mathbb{P}_{s}^{\prime}=0$, so the constraint $w_{l} \geq b$ is verified. Taking (4) into account, one has:

$$
\begin{aligned}
0=\mathbb{P}_{\tau}^{\prime} & =\left(P_{l}^{\prime} v^{\prime}\left(w_{l}\right)-P_{h}^{\prime} v^{\prime}\left(w_{h}\right)\right)\left(f(L)-L \cdot f^{\prime}(L)\right)-P_{l}^{\prime} v^{\prime}\left(w_{l}\right) \cdot \varepsilon \cdot f(L) \\
\mathbb{P}_{L}^{\prime} & =P_{l}^{\prime} v^{\prime}\left(w_{l}\right)(1-\varepsilon \tau) f^{\prime}(L)+\left(P_{l}^{\prime} v^{\prime}\left(w_{l}\right)-P_{h}^{\prime} v^{\prime}\left(w_{h}\right)\right)(1-\tau) L f^{\prime \prime}(L)
\end{aligned}
$$

From (A1) and $\mathbb{P}_{\tau}^{\prime}=0$, one has:

$$
P_{l}^{\prime} v^{\prime}\left(w_{l}\right)-P_{h}^{\prime} v^{\prime}\left(w_{h}\right)=\varepsilon \cdot P_{l}^{\prime} v^{\prime}\left(w_{l}\right) \frac{f(L)}{f(L)-L f^{\prime}(L)}>0
$$

Then, equations (A2), (A3) and (5) give:

$$
\mathbb{P}_{L}^{\prime}=\varepsilon(1-\tau) \cdot P_{l}^{\prime} v^{\prime}\left(w_{l}\right) \cdot f^{\prime}(L)\left(\frac{1-\varepsilon \cdot \tau}{\varepsilon(1-\tau)}-\frac{1}{\sigma(L)}\right)
$$

Since $\frac{\varepsilon-\varepsilon \tau}{1-\varepsilon \tau}<\varepsilon$, and $\varepsilon<\sigma(L)$, one gets $\mathbb{P}_{L}^{\prime}>0$. So, necessarily, one has at the maximum of program (10) without the constraints $s, \tau \geq 0, L=1, s=\tau(1-\varepsilon) f(1)$, so

$$
w_{h}=(1-\tau)\left(f(1)-f^{\prime}(1)\right) \quad \text { and } \quad w_{l}=(1-\tau) f^{\prime}(1)+\tau(1-\varepsilon) f(1)
$$

and therefore $\mathbb{P}(1, \tau, s)=\mathfrak{P}(\tau)$ where:

$$
\mathfrak{P}(\tau) \equiv P\left\{v\left[(1-\tau)\left(f(1)-f^{\prime}(1)\right)\right], v\left[(1-\tau) f^{\prime}(1)+\tau(1-\varepsilon) f(1)\right]\right\}
$$

and:

$$
\mathfrak{P}^{\prime}(\tau)=\left(P_{l}^{\prime} v_{l}^{\prime}-P_{h}^{\prime} v_{h}^{\prime}\right)\left(f(1)-f^{\prime}(1)\right)-\varepsilon \cdot P_{l}^{\prime} v_{l}^{\prime} \cdot f(1)
$$

Moreover, by linearity of $w_{l}$ and $w_{h}$ as function of $\tau$, strict concavity of $v($.$) and weak$ concavity of $P(.,$.$) function \mathfrak{P}($.$) is strictly concave. Since:$

$$
\varepsilon<\frac{P_{l}^{0 \prime} v_{l}^{0 \prime}-P_{h}^{0 \prime} v_{h}^{0 \prime}}{P_{l}^{0 \prime} v_{l}^{0 \prime}} \cdot \frac{f(1)-f^{\prime}(1)}{f(1)}
$$

one has $\mathfrak{P}^{\prime}(0)>0$, so the tax rate $\tau^{*}$ that maximizes $\mathfrak{P}(\tau)$ is strictly positive. Hence the solution to program (10) without the constraints $\tau, s \geq 0$ is necessarily $L=1, \tau=\tau^{*}$ and $s=s^{*}=\tau^{*}(1-\varepsilon) f(1)$. Finally, since $\tau^{*}>0$, one also has $s^{*}>0$, so $L=1, \tau=\tau^{*}$, $s=s^{*}$ solves program (10), including the constraints $s, \tau \geq 0$. 


\section{A.2 The Time Consistent case}

\section{Proof of proposition 2}

The best consistent policy solves:

$$
\begin{aligned}
\max _{w_{h}, w_{l}, b, s, \tau} & P\left(v\left(w_{h}\right), L \cdot v\left(w_{l}\right)+(1-L) v(b)\right) \\
\text { s.t. } \quad(6) \quad 0 & =(1-\varepsilon) \tau \cdot f(L)-L \cdot s-(1-L) b \\
\quad(7) \quad 0 & =(1-\varepsilon \cdot \tau) f(L)-w_{h}-L \cdot w_{l}-(1-L) b \\
w_{l} & \geq b, s \geq 0
\end{aligned}
$$

The first order conditions are:

$$
\begin{aligned}
& 0=P_{h}^{\prime} v^{\prime}\left(w_{h}\right)-\mu \quad 0=L\left\{P_{l}^{\prime} v^{\prime}\left(w_{l}\right)-\mu\right\} \\
& 0=(1-L)\left(P_{l}^{\prime} v^{\prime}(b)-\mu-\lambda\right) \\
& 0 \geq-L \cdot \lambda \quad \text { with } s \cdot(L \cdot \lambda)=0 \\
& 0=\{-\mu \cdot \varepsilon+\lambda \cdot(1-\varepsilon)\} f(L)
\end{aligned}
$$

Hence,

$$
P_{h}^{\prime} v^{\prime}\left(w_{h}\right)=P_{l}^{\prime} v^{\prime}\left(w_{l}\right)
$$

and $\lambda=\frac{\varepsilon}{1-\varepsilon} \mu>0$. It is therefore impossible to get an interior solution on $s$, so $s=0$. One also gets $v^{\prime}(b)>v^{\prime}\left(w_{l}\right)$, so $w_{l}>b$ and the constraint $w_{l} \geq b$ is verified.

Let us now show by contradiction that unemployment appears at equilibrium. If full employment prevails, no unemployment benefits would be distributed so no taxes would be levied according to the budget constraint (6) (recall $s=0$ ). Hence, one would get $w_{h}=f(1)-f^{\prime}(1)$ and $w_{l}=f^{\prime}(1)$. With such wages levels, conditions (A6) would not be met according to equation (9). So full-employment cannot prevails at equilibrium.

\section{Proof of proposition 3}

With the benchmark specification, equation (A6) becomes $p\left(w_{h}\right)^{-\lambda}=(1-p)\left(w_{l}\right)^{-\lambda}$, so $w_{h} / w_{l}=(p /(1-p))^{1 / \lambda}$. Moreover, at the TC equilibrium one gets $s=0$, so according to equations (3) and (4) $w_{h} / w_{l}=W_{h} / W_{l}=(\alpha /(1-\alpha)) L^{\frac{1}{\sigma}}$. Rearranging these two equations give (13).

\section{B The dynamic model}

\section{B.1 The Time Inconsistent case}

The Lagrangian of program (20) writes:

$$
\begin{aligned}
\mathcal{L} & =\sum_{t=0}^{+\infty} \delta^{t} P\left\{v\left(w_{h, t}\right), L_{t} \cdot v\left(w_{l, t}\right)+\left(1-L_{t}\right) v\left(b_{t}\right)\right\}+\sum_{t=0}^{+\infty} \delta^{t} \eta_{t}\left[\left(1-\tau_{t}\right) W_{t}^{L}+s_{t}-w_{l, t}\right] \\
& +\sum_{t=0}^{+\infty} \delta^{t} \kappa_{t}\left[f^{\prime}\left(L_{t}\right)+\delta \cdot \gamma\left(L_{t+1}-L_{t}\right)+\gamma\left(L_{t-1}-L_{t}\right)-W_{t}^{L}\right] \\
& +\sum_{t=0}^{+\infty} \delta^{t} \mu_{t}\left\{\left(1-\tau_{t}\right)\left[f\left(L_{t}\right)-\frac{\gamma}{2}\left(L_{t}-L_{t-1}\right)^{2}-L_{t} \cdot W_{t}^{L}\right]-w_{h, t}\right\} \\
& +\sum_{t=0}^{+\infty} \delta^{t} \lambda_{t}\left\{(1-\varepsilon) \tau_{t}\left[f\left(L_{t}\right)-\frac{\gamma}{2}\left(L_{t}-L_{t-1}\right)^{2}\right]-L_{t} \cdot s_{t}-\left(1-L_{t}\right) b_{t}\right\} \\
0 & \leq s_{t}, \tau_{t} \quad L_{t} \leq 1 \quad b_{t} \leq w_{l, t}
\end{aligned}
$$


First order conditions are:

$$
\begin{aligned}
0 & =P_{h}^{\prime} v^{\prime}\left(w_{h, t}\right)-\mu_{t} \quad 0=L_{t} \cdot P_{l}^{\prime} v^{\prime}\left(w_{l, t}\right)-\eta_{t} \\
0 & =\left(1-L_{t}\right)\left(P_{l}^{\prime} v^{\prime}\left(b_{t}\right)-\lambda_{t}\right) \quad 0=\left(\eta_{t}-L_{t} \cdot \mu_{t}\right)\left(1-\tau_{t}\right)-\kappa_{t} \quad\left(w_{t} / W_{t} / w_{t}\right) \\
0 & \geq \eta_{t}-L_{t} \cdot \lambda_{t} \quad \text { with } s_{t}\left[\eta_{t}-L_{t} \cdot \lambda_{t}\right]=0 \\
0 & =\lambda_{t}(1-\varepsilon)\left[f\left(L_{t}\right)-\frac{\gamma}{2}\left(L_{t}-L_{t-1}\right)^{2}\right]-\eta_{t} \cdot W_{t}^{L} \\
& -\mu_{t}\left[f\left(L_{t}\right)-\frac{\gamma}{2}\left(L_{t}-L_{t-1}\right)^{2}-L_{t} \cdot W_{t}^{L}\right] \\
0 & \leq P_{l}^{\prime}\left[v\left(w_{l, t}\right)-v\left(b_{t}\right)+\kappa_{t}\left[f^{\prime \prime}\left(L_{t}\right)-(1+\delta) \gamma\right]+\left(\kappa_{t-1}+\kappa_{t+1} \cdot \delta\right) \gamma\right. \\
& +\mu_{t}\left(1-\tau_{t}\right)\left[f^{\prime}\left(L_{t}\right)-\gamma\left(L_{t}-L_{t-1}\right)-W_{t}^{L}\right]+\delta \cdot \mu_{t+1}\left(1-\tau_{t+1}\right) \cdot \gamma\left(L_{t+1}-L_{t}\right) \\
& +\lambda_{t}\left\{(1-\varepsilon) \tau_{t}\left[f^{\prime}\left(L_{t}\right)-\gamma\left(L_{t}-L_{t-1}\right)\right]-s_{t}+b_{t}\right\}+\delta \cdot \lambda_{t+1} \cdot \gamma\left(L_{t+1}-L_{t}\right)
\end{aligned}
$$

Eliminating the multipliers with the four first conditions, the remaining conditions at a steady-state are:

$$
\begin{aligned}
0 & \geq L \cdot P_{l}^{\prime}\left[v^{\prime}\left(w_{l}\right)-v^{\prime}(b)\right]=\mathbb{P}_{s}^{\prime} \\
0 & =P_{l}^{\prime} v^{\prime}(b)(1-\varepsilon) f(L)-P_{h}^{\prime} v^{\prime}\left(w_{h}\right)\left[f(L)-L f^{\prime}(L)\right]-P_{l}^{\prime} v^{\prime}\left(w_{l}\right) L f^{\prime}(L)=\mathbb{P}_{\tau}^{\prime} \\
0 & \leq P_{l}^{\prime}\left[v\left(w_{l}\right)-v(b)\right]+\left(P_{l}^{\prime} v^{\prime}\left(w_{l}\right)-P_{h}^{\prime} v^{\prime}\left(w_{h}\right)\right)(1-\tau) L f^{\prime \prime}(L) \\
& +P_{l}^{\prime} v^{\prime}(b)\left\{\tau(1-\varepsilon) \cdot f^{\prime}(L)-s+b\right\}=\mathbb{P}_{L}^{\prime}
\end{aligned}
$$

So the problem of finding a stationary equilibrium under long-term commitment is exactly equivalent to the one of finding an equilibrium in the static TI model.

\section{B.2 The "short term" case}

Let $\mathbb{W}\left(L_{t}, L_{t-1}\right)$ denotes (the linear approximation of) the right hand side of (21). At a steady-state, one gets $\mathbb{W}(L, L)=f^{\prime}(L)$, whereas partial derivatives of $\mathbb{W}$ are:

$$
\mathbb{W}_{1}^{\prime}=f^{\prime \prime}(L)-\gamma\left(1+\delta-\delta \cdot \theta^{\prime}\right) \quad \mathbb{W}_{2}^{\prime}=\gamma
$$

Program (22) can be rewritten as:

$$
\begin{aligned}
\Omega\left(L_{t-1}\right) & =\max \quad P\left(v\left(w_{h, t}\right), L_{t} v\left(w_{l, t}\right)+\left(1-L_{t}\right) v\left(b_{t}\right)\right)+\delta \cdot \Omega\left(L_{t}\right) \\
\text { s.t. : } \quad 0 & =\left(1-\tau_{t}\right)\left(f\left(L_{t}\right)-\frac{\gamma}{2}\left(L_{t}-L_{t-1}\right)^{2}-\mathbb{W}\left(L_{t}, L_{t-1}\right) \cdot L_{t}\right)-w_{h, t} \quad\left(\mu_{t}\right) \\
0 & =\left(1-\tau_{t}\right) \mathbb{W}\left(L_{t}, L_{t-1}\right)+s_{t}-w_{l, t} \\
0 & =(1-\varepsilon) \tau_{t}\left[f\left(L_{t}\right)-\frac{\gamma}{2}\left(L_{t}-L_{t-1}\right)^{2}\right]-L_{t} \cdot s_{t}-\left(1-L_{t}\right) b_{t} \\
0 & \leq s_{t}, \tau_{t} \quad L_{t} \leq 1 \quad \text { given : } \quad L_{t-1} \quad \text { and } \quad \forall k \geq 1 \quad L_{t+k}=\theta^{c}\left(L_{t+k-1}\right)
\end{aligned}
$$

The first order conditions are:

$$
\begin{aligned}
& 0=P_{h}^{\prime} v^{\prime}\left(w_{h, t}\right)-\mu_{t} \quad 0=L_{t} \cdot P_{l}^{\prime} v^{\prime}\left(w_{l, t}\right)-\eta_{t} \\
& 0=\left(1-L_{t}\right)\left(P_{l}^{\prime} v^{\prime}\left(b_{t}\right)-\lambda_{t}\right) \quad 0 \geq \eta_{t}-L_{t} \cdot \lambda_{t} \\
& \left(w_{h}, t / w_{l}, t\right) \\
& \left(b_{t} / s_{t}\right) \\
& 0=\left[\lambda_{t}(1-\varepsilon)-\mu_{t}\right]\left[f\left(L_{t}\right)-\frac{\gamma}{2}\left(L_{t}-L_{t-1}\right)^{2}\right]+\left(\mu_{t} \cdot L_{t}-\eta_{t}\right) \cdot \mathbb{W} \\
& 0 \leq P_{l}^{\prime}\left[v\left(w_{l, t}\right)-v\left(b_{t}\right)\right]+\delta \cdot \Omega^{\prime}\left(L_{t}\right)+\mu_{t}\left(1-\tau_{t}\right)\left\{f^{\prime}\left(L_{t}\right)-\gamma\left(L_{t}-L_{t-1}\right)-\mathbb{W}-L_{t} \cdot \mathbb{W}_{1}^{\prime}\right\} \\
& +\eta_{t}\left(1-\tau_{t}\right) \mathbb{W}_{1}^{\prime}+\lambda_{t}\left\{(1-\varepsilon) \tau_{t}\left[f^{\prime}\left(L_{t}\right)-\gamma\left(L_{t}-L_{t-1}\right)\right]-s_{t}+b_{t}\right\}
\end{aligned}
$$


and the envelope condition is:

$$
\Omega^{\prime}\left(L_{t-1}\right)=\left(\eta_{t}-\mu_{t} \cdot L_{t}\right)\left(1-\tau_{t}\right) \mathbb{W}_{2}^{\prime}+\left(\left(1-\tau_{t}\right) \mu_{t}+(1-\varepsilon) \tau_{t} \lambda_{t}\right) \gamma\left(L_{t}-L_{t-1}\right)
$$

Let $L=L^{\mathrm{c}}$ be a stable steady-state equilibrium. Hence, one has $\left|\theta^{\prime}\left(L^{\mathrm{c}}\right)\right|<1$. Eliminating the multipliers with the three first conditions, using the envelope condition, a steady-state equilibrium necessarily verifies:

$$
\begin{aligned}
0 & \geq L \cdot P_{l}^{\prime}\left(v^{\prime}\left(w_{l}\right)-v^{\prime}(b)\right)=\mathbb{P}_{s}^{\prime} \\
0 & =\left[P_{l}^{\prime} v^{\prime}(b)(1-\varepsilon)-P_{h}^{\prime} v^{\prime}\left(w_{h}\right)\right] f(L)+\left(P_{h}^{\prime} v^{\prime}\left(w_{h, t}\right)-P_{l}^{\prime} v^{\prime}\left(w_{l}\right)\right) L \cdot f^{\prime}(L)=\mathbb{P}_{\tau}^{\prime} \\
0 & \leq P_{l}^{\prime}\left[v\left(w_{l}\right)-v(b)\right]+P_{l}^{\prime} v^{\prime}(b)\left\{(1-\varepsilon) \tau f^{\prime}(L)-s+b\right\} \\
& +\left[P_{l}^{\prime} v^{\prime}\left(w_{l}\right)-P_{h}^{\prime} v^{\prime}\left(w_{h}\right)\right](1-\tau) \cdot L \cdot\left(f^{\prime \prime}(L)-\gamma\left(1-\delta \cdot \theta^{\prime}\right)\right)
\end{aligned}
$$

One hence get the same first order conditions than in the static case with credible binding commitments, except that $f^{\prime \prime}(L)$ is now replaced by $\mathbb{W}_{1}^{\prime}+\delta \cdot \mathbb{W}_{2}^{\prime}=f^{\prime \prime}(L)-\gamma\left(1-\delta \cdot \theta^{\prime}\right)$. Consider then the steady-state solution to $(22)$ without the constraint $s>0$. One gets $w_{l}=b$, so equation (A3) applies and the condition on $L$ becomes:

$$
0 \leq \frac{1-\varepsilon \tau}{\varepsilon(1-\tau)}-\frac{1}{\sigma(L)}-\gamma\left(1-\delta \cdot \theta^{\prime}\right) \frac{f(L) \cdot L}{\left(f(L)-L f^{\prime}(L)\right) f^{\prime}(L)}
$$

Given (5), this leads to:

$$
0 \leq \frac{1-\varepsilon \tau}{\varepsilon(1-\tau)}-\frac{1}{\sigma(L)}\left[1+\gamma \frac{1-\delta \cdot \theta^{\prime}}{-f^{\prime \prime}(L)}\right]
$$

Provide $\varepsilon<\varepsilon^{\mathrm{c}}$ and $\left|\theta^{\prime}\left(L^{\mathrm{c}}\right)\right|<1$, one has:

$$
\frac{1}{\sigma(L)}\left[1-\gamma \frac{1-\delta \cdot \theta^{\prime}}{f^{\prime \prime}(L)}\right]<\frac{1}{\sigma(L)}\left[1-\gamma \frac{1+\delta}{f^{\prime \prime}(L)}\right]<\frac{1}{\varepsilon} \leq \frac{1-\varepsilon \tau}{\varepsilon(1-\tau)}
$$

so the constraint $L \leq 1$ is binding. The solution to (22) without the constraint $s_{t}>0$ is therefore $L=1, \tau=\tau^{*}$ and $s=s^{*}$. Finally, since $\varepsilon<\frac{P_{l}^{0 \prime} v_{l}^{0 \prime}-P_{h}^{0 \prime} v_{h}^{0 \prime}}{P_{l}^{0 \prime} v_{l}^{0 \prime}} \cdot \frac{f(1)-f^{\prime}(1)}{f(1)}$, this program is solved with $\tau=\tau^{*}>0$ and $s=s^{*}>0$, which also solves program (22) without the constraint $s_{t}>0$.

\section{B.3 The "lack of credibility" case}

The Lagrangian of program (24) writes as:

$$
\begin{aligned}
\mathcal{L} & =P\left(v\left(w_{h, t}\right), L_{t} v\left(w_{l, t}\right)+\left(1-L_{t}\right) v\left(b_{t}\right)\right)+\delta \cdot \Omega\left(L_{t}\right) \\
& +\lambda_{t}\left\{(1-\varepsilon) \tau_{t}\left[f\left(L_{t}\right)-\frac{\gamma}{2}\left(L_{t}-L_{t-1}\right)^{2}\right]-L_{t} \cdot s_{t}-\left(1-L_{t}\right) b_{t}\right\} \\
& +\mu_{t}\left\{\left(1-\varepsilon \cdot \tau_{t}\right)\left[f\left(L_{t}\right)-\frac{\gamma}{2}\left(L_{t}-L_{t-1}\right)^{2}\right]-w_{t}^{h}-L_{t} \cdot w_{t}^{l}-\left(1-L_{t}\right) b_{t}\right\}
\end{aligned}
$$

The first order conditions are:

$$
\begin{array}{lr}
0=P_{h}^{\prime} v^{\prime}\left(w_{h, t}\right)-\mu_{t} \quad 0=L_{t}\left\{P_{l}^{\prime} v^{\prime}\left(w_{l, t}\right)-\mu_{t}\right\} & \left(w_{h}, t / w_{l}, t\right) \\
0=\left(1-L_{t}\right)\left(P_{l}^{\prime} v^{\prime}\left(b_{t}\right)-\mu_{t}-\lambda_{t}\right) & \left(b_{t}\right) \\
0 \geq-L_{t} \cdot \lambda_{t} \quad \text { with } s_{t} \cdot\left(L_{t} \cdot \lambda_{t}\right)=0 & \left(s_{t}\right) \\
0=\left[\lambda_{t}(1-\varepsilon)-\mu_{t} \cdot \varepsilon\right]\left[f\left(L_{t}\right)-\frac{\gamma}{2}\left(L_{t}-L_{t-1}\right)^{2}\right] & \left(\tau_{t}\right)
\end{array}
$$


Hence, the solution is similar to the static case with non binding commitment (see Appendix 2). One gets:

$$
P_{h}^{\prime} v^{\prime}\left(w_{h, t}\right)=P_{l}^{\prime} v^{\prime}\left(w_{l, t}\right)
$$

and $\lambda_{t}=\frac{\varepsilon}{1-\varepsilon} \mu_{t}>0$. It is therefore impossible to get an interior solution on $s_{t}$, so $s_{t}=0$ for any $t$. One also gets $v^{\prime}\left(b_{t}\right)>v^{\prime}\left(w_{l, t}\right)$, so $w_{l, t}>b_{t}$ and the constraint $w_{l, t} \geq b_{t}$ is verified. Finally, the equations defining any steady-state (with $L_{t}=L_{t-1}$ ) exactly corresponds to the one defining the political outcome in the static case with no binding commitment (see Appendix 2). Hence, there is no steady-state without unemployment.

\section{Data sources}

The data were downloaded from three websites.

First, I use data by Nickell and Nunziata (2001) for the employment rate EPOP, the standardized unemployment rate $U R$, the acceleration in Money supply $\Delta^{2} M^{s}$, the real interest rate $R I R L$, the terms of trade $T T S$ and for the Time varying measures of employment protection $E P$ and coordination measures $C O$. Data, data sources and definitions are available at

http://cep.lse.ac.uk/pubs/download/data0502.zip.

Second, I have computed inequality measures $P 50 / P 10$ from the OECD website on percentile distribution of gross earnings (for men and women). See the menu following:

http://www1.oecd.org/scripts/cde/ for data and data sources.

Third I use measures of political influences given by Duan Swank on http://www.marquette.edu/polisci/Swankpart5099.xls.

The variable $P O L S W A N K$ is defined as:

$$
P O L S W A N K_{i, t}=L E F T V_{i, t}-R I G H T V_{i, t}
$$

where $L E F T V_{i, t}\left(R I G H T V_{i, t}\right)$ stands for left party (right party) votes as a percent of total votes (see further details and data sources on:

http://www.marquette.edu/polisci/Swankpart5099code.pdf). The variable TRENDSWA is built according to

TRENDWSWA $A_{i, t}= \begin{cases}0 & \text { if } t=1960 \\ T R E N D W S W A_{i, t-1}+P O L S W A N K_{i, t-1} & \text { else }\end{cases}$

Deleting the missing values (in particular for $P 50 P 10$ and $\Delta^{2} M^{s}$ ), and the countries with a single observation (not relevant for within estimations) the 236 remaining observations are given in Table 2

\section{References}

[1] Agell, J. and K. E. Lommerud, 1997, "Minimum wages and the incentives for skill formation", Journal of Public Economics, vol. 64, pp. 25-40.

[2] Algan, Y, P. Cahuc and A. Zylberberg, 2002, "Public Employment and Labour Market performance", Economic Policy, 34, pp. 9-65. 


\begin{tabular}{|l|l||l|l|}
\hline Country & Years & Country & Years \\
\hline Australia & $1975-1995$ & Japan & $1975-1995$ \\
\hline Belgium & $1985-1995$ & Netherlands & $1977-1995$ \\
\hline Canada & $\begin{array}{l}1967,1973,1981,1986, \\
1988,1990-1994\end{array}$ & New Zealand & 1984,1986 \\
\hline Denmark & $1980-1990$ & & \\
\hline Finland & $\begin{array}{l}1977,1980,1983,1986- \\
\end{array}$ & Sweden & $1975,1978,1980-1995$ \\
\hline France & 1995 & Switzerland & $1991-1995$ \\
\hline Germany & $1984-1995$ & United Kingdom & $1970-1995$ \\
\hline Italy & $1986-1995$ & United States & $1973-1995$ \\
\hline
\end{tabular}

Table 2: observations

[3] Allen, S., 1987, "Taxes, Redistribution, and the Minimum Wage: a Theoretical Analysis", Quarterly Journal of Economics, vol. 101, pp. 477-89.

[4] Alesina, A., and N. Roubini with G. Cohen, Political cycles and the macroeconomy, MIT Press, Cambridge, US.

[5] Barro, R., and D. Gordon, 1983, "A Positive Theory of Monetary Policy in a Natural Rate Model", Journal of Political Economy, vol. 91, pp. 589-610.

[6] Bellot, M. and J. Van Ours, 2000, "Does the recent success of some OECD countries in lowering their unemployment rates lie in the clever design of their labor market reforms ?", Working Paper 2000-40, CentER for Economic Research, Department of Economics, Tilburg University, Netherlands.

[7] Bertola, G., F. Blau and L. Kahn, 2001, "Comparative Analysis of Labor Market Outcomes: Lessons for the US from International Long-Run Evidence", mimeo.

[8] Blanchard, O. J. and J. Wolfers (2000), "The Role of Shocks and Institutions in the Rise of European Unemployment", Economic Journal, vol. 110, pp. C1-C33.

[9] Boadway. R. and N. Marceau, 1994, "Minimum Wage Legislation and Unemployment Insurance as Instruments for Redistribution", Scandinavian Journal of Economics, vol. 96(1), pp. 67-81.

[10] Bresson, G., F. Kramarz and P. Sevestre, 1996, "Dynamic labour demand models", chapter 25 in L. Matyas and P. Sevestre, The Econometrics of Panel Data: a Handbook of the Theory with applications, Second revised version, Kluwer Academic Press.

[11] Cahuc, P. and P. Michel, 1996, "Minimum Wage Unemployment and Growth", European Economic Review, vol. 40, pp. 1463-1482.

[12] Cahuc, P., A. Saint-Martin and A. Zylberberg, 2001, "The Consequences of the Minimum Wages when other, Wages are Bargained Over", European Economic Review, vol. $45(2)$, pp. 337-352.

[13] Cahuc, P. and A. Zylberberg, 2004, Labor economics, MIT Press. 
[14] Card, D. and A. Krueger, 1994, "Minimum Wages and Employment: a case study of the fast-food industry in New Jersey and Pennsylvania", American Economic Review, vol. 84(4), pp.772-793.

[15] Coate, S. and S. Morris, 1995, "On the form of transfers to special interests", Journal of Political Economy, 103(6), pp. 1210-1235.

[16] Cohen, D. and P. Michel, 1988, "How should control theory be used to calculate a time consistent government policy?", Review of Economic Studies, vol. 55, pp. 263-274.

[17] Daveri, F. and G. Tabellini, 2000, "Unemployment, Growth and Taxation in Industrial Countries", Economic Policy, vol. 30 pp. 49-104.

[18] Decreuse, B. and B. Wigniolle, 2002, "”, mimeo, EUREQua Paris 1.

[19] Dolado, J., F. Kramarz, S. Machin, A. Manning, D. Margolis, and C. Teulings, 1996, "The Economic Impact of Minimum Wages in Europe", Economic Policy, vol. 23, pp. 317-372.

[20] Drèze, J. H. et C. Gollier, 1993, "Risk sharing on the labour market and second best wage rigidities", European Economic Review, vol. 37, pp. 1457-1482.

[21] Drèze, J. and Malinvaud, E., 1994, "Growth and Employment: The scope of a European Initiative", European Economic Review, vol. 38 (3-4), pp. 489-504.

[22] Epstein, G. and S. Nitzan, 1999, "The Endogenous Determination of Minimum Wage", IZA working paper 73.

[23] Grossman, G. and E. Helpman, 1994, "Protection for sales", American Economic Review, vol. 84, pp. 833-850.

[24] Guesnerie, R. and K. Roberts, 1987, "Minimum Wage Legislation as Second Best Policy", European Economic Review, vol. 31 pp. 490-498.

[25] Hamermesh, D., 1993, Labour Demand, Princeton University Press.

[26] Hungerbühler, M., Lehmann, E., Parmentier, A. and Van der Linden, B., 2006, "Optimal Redistributive Taxation in a Search Equilibrium Model", Review of Economic Studies, Forthcoming.

[27] Krusell, P., V. Quadrini and J-V Rios-Rull, 1997, "Politico-economic equilibrium and economic growth", Journal of Economic Dynamics and Control, vol. 21, pp. 243-272.

[28] Kydland F. E. and E. Prescott, 1977, "Rules rather than discretion. The inconsistency of optimal plans", Journal of Political Economy, vol. 85, pp. 473-492.

[29] Lindbeck, A. and J. Weibull, 1987, "Balanced-Budget Redistribution as the Outcome of Political Competition", Public Choice, vol. 52, pp. 273-297.

[30] Manning, A., 2003, Monopsony in motion: Imperfect Competition in Labor Markets, Princeton University Press, Princeton, US.

[31] Nickell, S.,1997, "Unemployment and Labor Market Rigidities: Europe versus North America", Journal of Economic Perspective, vol. 11-3, pp. 55-74. 
[32] Nickell, S., L. Nunziata, 2001, Labour market database, CEP, LSE, September 2001 http://cep.lse.ac.uk/pubs/download/data0502.zip

[33] Nickell, S., L. Nunziata, W. Ochel and G. Quintini, 2001, "The Beveridge Curve, Unemployment and Wage in the OECD", CEP Discussion Paper 502.

[34] Nickell, S. and J. Van Ours, 2000, "The Netherlands and the United Kingdom: a European Unemployment Miracle ?", Economic Policy, vol. 30, pp. 137-180.

[35] OECD, 1996, Employment Outlook, OECD Press, Paris

[36] OECD, 1998, Employment Outlook, OECD Press, Paris.

[37] Persson, T. and G. Tabellini, 2000, Political Economy: Explaining Economic Policy, MIT Press, Cambridge, US.

[38] Piketty, T., 1999, "Can fiscal redistribution undo skill-biased technical change ? Evidence from the French experience", European Economic Review, vol. 43, pp. 839-851.

[39] Salanié, B., 2003, The economics of taxation, MIT Press, Cambridge, US.

[40] Saint Paul, G. ,1994, "Do labor market rigidities fulfill redistributive objectives ?", I.M.F. Staff Papers, vol. 41(4), pp. 624-642.

[41] Saint-Paul, G., 1996a, "Labor Market Rigidities and the Cohesion of the Middle Class", International Tax and Public Finance, vol. 3, pp. 385-395.

[42] Saint-Paul, G., 1996b, "Exploring the political economy of labour market institutions", Economic Policy, vol. 23, pp. 265-315.

[43] Saint-Paul, G., 2000, The Political Economy of Labour Market Institutions, Oxford University Press, Oxford, UK.

[44] Scarpetta, S., 1996, "Assessing the role of labour market policies and institutional settings on unemployment: A cross-country study, OECD Economic Studies, vol. 26, pp. $43-82$.

[45] Sobel, R., 1999, "Theory and Evidence on the Political Economy of the Minimum Wage", Journal of Political Economy, vol. 107(4), pp. 761-785.

[46] Stigler, G., 1946, "The economics of minimum wage legislation", American Economics Review, vol. 36, pp. 358-365. 